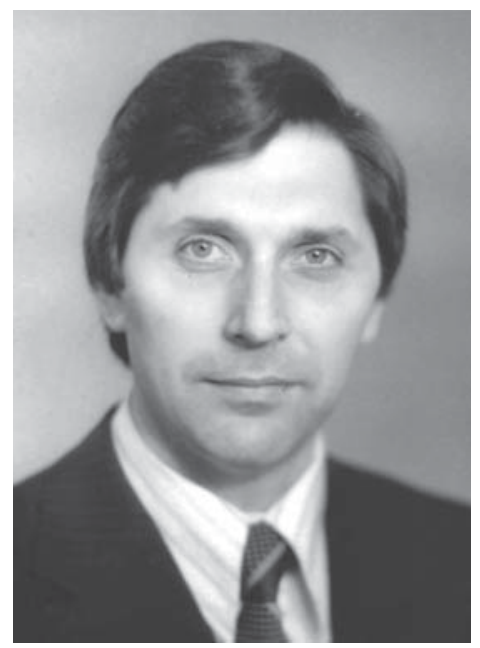

Victor Isac (1943 - 1995)

\title{
HAPPINESS OF EVOCATION
}

\section{Victor Isac would have reached the 70 years}

Victor Isac was a teacher by vocation, scientist and man of culture, who served with honor and honesty education and our national school by writing some prestigious books with didactical or monographic character, through excruciating teacher activity, bringing a good name to the country and leaving behind him an unforgettable memory. In his short-life (July 8, 1943 - October 3 1995) he succeeded to publish more than 220 scientific and scientific-didactic papers, including 14 monographs, textbooks, and studies. Alongside the noble toil of teacher and researcher he has assumed the function of Dean, leading the Faculty of Chemistry at the State University of Moldova from 1981 until the last moment of his life. It seems that God loved too much his soul, so that he was snatched from us so early.

Born in the village Drepcauti, district Edinet, he graduated with honors the Faculty of Chemistry (1969) and obtained his doctorate (1972) at the State University of Moldova with the Ph.D thesis ,The decomposition of hydrogen peroxide catalyzed by trivalent iron complexes and divalent manganese with triethylenetetramine and histidine "(1973). His work has been highly appreciated by academician Anthony Ablov in his opinion as the first official reviewer on the thesis defense. The second thesis "The coordination compounds of manganese and iron in redox catalysis" (1990) has brought the scientific title of Doctor Habilitatus in chemistry. Since 1992 he holds the title of university professor.

Victor Isac was a consecrated researcher who pulled deep furrows on the field of physical chemistry. The coordinative systems with catalyses, peroxides and oxides proprieties studied by him come today the ambient safeguarding threatened by a too excessive pollution. I worked with this distinguished scientist, publishing in collaboration with him 36 scientific papers and I have to confess that this communion was for me, and I hope for him, too, a necessity and a real delight.

The works achieved by this hardworking researcher refer to some issues of stringent actuality such as the activation of molecular oxygen and hydrogen peroxide by the coordination compounds of iron and manganese (the complex of trivalent iron with triethylenetetramine, for example, often is rightfully nicknamed "inorganic catalase"), establishment the legalities that govern these processes, the elucidation of reactions mechanisms and designating the ways of using the eventual results.

In the molecular biology epoch of glory, the modeling of the living specific processes through coordinative systems containing iron or manganese ion, a helatofor (polyamine, amino acid, etc.), an organic substrate occurs as handsome as it is and troublesome, because it contains the entire spectrum of investigations: from fundamental research through advanced research, including technological transfer, to implementation in practice.

In terms of fundamental science Professor Victor Isac had argued and developed new concepts on the likelihood of initiation phase in homogeneous catalysis and the route of process for the catalytic oxidation of colorings and other organic substrates, he introduced new concepts regarding the nature of the reaction in available reactant volume, unleashed by the active catalytic center and is responsible itself for the catalytic act. Practically, he elaborated new kinetic methods of analysis (domain nicknamed and as catalimetrie) of the micro quantities of manganese and iron 
which satisfy the requirements of precision, simplicity and rapidity, as well as one procedure for catalytic purification of solutions with large quantities of hydrogen peroxide.

The achievements of Professor Victor Isac were highly appreciated by granting in 1998 (post-mortem), side by side with Professor Alexei Saciov, whose disciple is, and with academician Gheorghe Duca, of State Prize of Republic of Moldova in Science, Technology and the Production for the cycle of papers "The fundamental and applied aspects of the homogeneous catalysis processes."

It would be a pity not to evoke in these pages the moral being and human dimension of this unforgettable friend and colleague. He was tall fitly framed together in an athletic figure, he had a safe and calm step, but his blue eyes, vivid and bright, had emanating gentleness, wisdom and inner beauty. Elegant in motion, delicate - more specifically, genteel - in appreciations, endowed by nature with the faculty of the mind to understand easily, quickly and in depth all that had been happening around, whatever may have been the subject of discussion, he knew how to reach the proposed in all circumstances. He manifested a great courage, but, also, a maximum objectivity and self-control in all his actions, leaving aside the personal interest, emotions, and feelings. His inexhaustible workforce, destined by God with the boundless love for those nearby - colleagues, $\mathrm{PhD}$ students, students, pupils - it was a man of total passion, spread all over nobility, tenderness, honesty and dignity. To these is added his communicability, who had generated solid friendships, reliable and beautiful relations and which had continued until the last moments of his life. The Department of Chemistry will still feel great and irreparable empty left by his untimely disappearance.

That certain such was to be the image of the Victor Isac comes to confirm the following testimony. It was in 1967. Faculty of Chemistry starts the distribution of graduates. Lieutenant-colonel at department of personnel of Academy of Sciences and the author of these rows - then deputy director for scientific work at the Institute of Chemistry - was to fill vacancies for research and doctoral studies with young specialists. The first among graduates appeared before the Commission Victor Isac and immediately announced that he will remain at the Department of Physical Chemistry. Military-"cadrovic" flinch and whisper my ear: Here, it's "frame" no the joke! It seems that he was spellbound of a the vigorous figure of graduate while the faculty leadership had saw in Victor Isac the embodiment of a brilliant intelligence, a moderate temperament and sublime character dominated by the modesty, magnanimity and virtue. And all were right.

During my time as a President of Commission for license exams and theses of High School I was given to meet with teachers that view in person of the student an intruder, to be held "in the bridle" always persecuting him. This antagonism in teacher-student relationship seems too obsolete and hazardously from the belief that teachers themselves have to draw benefits from the scientific contact with their students. This antagonism in teacher-student relationship seems too obsolete and hazardously from the belief that teachers themselves have to draw benefits from the scientific contact with their learners, treating them as if they were adults. In this context professor Victor Isac was to be the kind of parent for students, who always put his shoulder to facilitate the way to a younger colleague called to carry forward the torch of research in chemistry, i.e. to achieve what the teacher was unable to do. Without fail, perhaps without knowing, Victor Isac has followed exhortation and counsel from the First Catholic Epistle of Apostle St. Peter: "Feed the herd of God, which is among you, taking the oversight thereof, not by constraint, but willingly; not for filthy lucre, but of a ready mind".

Victor Isac was always to make considerable efforts for good academic training and have great fulfillments. Through his lectures in physical chemistry, writing textbooks and compendiums for discipline, engagement of students in research, he succeeded in promoting the much coveted university triad of: 1) the transmission of knowledge, 2) development of development of the free flight for convergent and divergent thinking, 3) the formation of some personalities, future professionals, at large scale. Thus succeeds to give brightness discipline that served with honor and devotion. Maybe, it can therefore has scored the so quickly to vouchsafe of all scientific and educational titles to Doctor Habilitatus in Chemistry and University Professor and enter into the first rows of the cohort of teachers of the highest quality.

Victor Isac came the sublime understanding that the intellectual potential of the nation is in decline and that only the valence and lucidity of the young generation resides our future. The scientific advice even from birth of this "CHIMCONT" was appointed as a Dean of the Faculty of Chemistry Victor Isac. And it was in the auspicious hour. It soon appeared a set of textbooks signed by Svetlana Kudritki, Boris Pasecinic, Galina Dragalina, Nadejda Velisco Peter Chetrus, Victor Isac, in which authors took everything they found most useful from the worldwide practice and added to it their own experience acquired in teaching at all levels from us. In this context, a special mention deserves the elaboration by Victor Isac together with professors from Romania, experienced specialists of some university textbooks such as: "Physical Chemistry: Chemical kinetics and catalysis" (Chisinau, Science, 1994, 639 pages), authors Victor Isac and Natalia Hurduc; "Physical Chemistry: Practical Applications" (Chisinau: Science, 1995, 759 pages), authors Victor Isac, Ana Onu, Cornelia Tudoreanu and George Nemțoi, "Physical Chemistry. Electrochemistry "(Chisinau: Science, 1997, 479 pages), authors George Nemtoi and Victor Isac.

With the participation of Professor Victor Isac four scientific-didactic conferences were organized in which chemistry teachers from middle schools, high schools, colleges and institutions of higher education from Romanian and 
universal space participated. At the last Conference held in the spring of 1998 for the participants it was hard to imagine that Victor Isac is no more. To cover somehow this gap were ad-hoc printed and distributed among participants the few materials about life and activity of more regretted professor and scholar.

It always found among students chairing the Chemistry Olympiads in the country and activating in the structure of the selection boards abroad Olympiads. Professor Alexander Cecal from University of Iasi (he, also, Dean of the Faculty of Chemistry) once had confessed that Victor Isac was more waited and appreciated at International Olympiads and that when he was to go into the shadows the absence of this great teacher was felt in full.

The notorious scholar conscious that only in love and harmony can be done the great things; Victor Isac always loved with passion his colleagues and with a fine and bouncy calligraphy - proof of a given alloy from nobility and intellect - used to give autographs to others. Here's what he had written on the title page of the book "The coordination compounds of manganese in catalysis"(Chisinau: Science, 1990, 322 pages), elaborated in collaboration with his magistrate Alexei Saciov "The highly esteemed Prof. Dr. Dumitru Batir with much respect and wishes of good health and new achievements". And so he wishes to everyone health, exactly what he had not.

Dumitru BATÎR,

Doctor Habilitatus in chemistry, university professor

State Prize Laureate 